\title{
Decline in physical activity, disability and pain-related fear in sub-acute low back pain.
}

Citation for published version (APA):

Verbunt, J. A. M. C. F., Sieben, J. M., Seelen, H. A. M., Vlaeyen, J. W. S., Bousema, E. J., van der Heijden, G. J., \& Knottnerus, J. A. (2005). Decline in physical activity, disability and pain-related fear in sub-acute low back pain. European Journal of Pain, 9(4), 417-425.

https://doi.org/10.1016/j.ejpain.2004.09.011

Document status and date:

Published: 01/01/2005

DOI:

10.1016/j.ejpain.2004.09.011

Document Version:

Publisher's PDF, also known as Version of record

Document license:

Taverne

Please check the document version of this publication:

- A submitted manuscript is the version of the article upon submission and before peer-review. There can be important differences between the submitted version and the official published version of record.

People interested in the research are advised to contact the author for the final version of the publication, or visit the DOI to the publisher's website.

- The final author version and the galley proof are versions of the publication after peer review.

- The final published version features the final layout of the paper including the volume, issue and page numbers.

Link to publication

\footnotetext{
General rights rights.

- You may freely distribute the URL identifying the publication in the public portal. please follow below link for the End User Agreement:

www.umlib.nl/taverne-license

Take down policy

If you believe that this document breaches copyright please contact us at:

repository@maastrichtuniversity.nl

providing details and we will investigate your claim.
}

Copyright and moral rights for the publications made accessible in the public portal are retained by the authors and/or other copyright owners and it is a condition of accessing publications that users recognise and abide by the legal requirements associated with these

- Users may download and print one copy of any publication from the public portal for the purpose of private study or research.

- You may not further distribute the material or use it for any profit-making activity or commercial gain

If the publication is distributed under the terms of Article $25 \mathrm{fa}$ of the Dutch Copyright Act, indicated by the "Taverne" license above, 


\title{
Decline in physical activity, disability and pain-related fear in sub-acute low back pain
}

\author{
Jeanine A. Verbunt ${ }^{\mathrm{a}, \mathrm{b}, *}$, Judith M. Sieben ${ }^{\mathrm{c}}$, Henk A.M. Seelen ${ }^{\mathrm{a}, \mathrm{b}}$, \\ Johan W.S. Vlaeyen ${ }^{\text {b,d,e }}$, Eric J. Bousema ${ }^{b}$, Geert J. van der Heijden ${ }^{f}$, \\ J. André Knottnerus ${ }^{\mathrm{c}}$ \\ ${ }^{a}$ Rehabilitation Foundation Limburg, P.O. Box 88, 6430 AB Hoensbroek, The Netherlands \\ ${ }^{\mathrm{b}}$ Institute for Rehabilitation Research, P.O. Box 192, 6430 AD Hoensbroek, The Netherlands \\ c Department of General Practice, Maastricht University, P.O. Box 616, 6200 MD Maastricht, The Netherlands \\ ${ }^{\mathrm{d}}$ Department of Medical, Clinical, and Experimental Psychology, Maastricht University, P.O. Box 616, 6200 MD Maastricht, The Netherlands \\ ${ }^{\mathrm{e}}$ Pain Management and Research Center, University Hospital Maastricht, P.O. Box 5800, 6202 AZ Maastricht, The Netherlands \\ ${ }^{\mathrm{f}}$ Julius Center for Health Sciences and Primary Care, University Medical Center Utrecht, P.O. Box 85500, 3508 GA Utrecht, The Netherlands
}

Received 31 May 2004; accepted 28 September 2004

Available online 29 April 2005

\begin{abstract}
Aim of investigation: To evaluate whether a perceived decline in the level of physical activity after the onset of pain (PAD) is more appropriate in the explanation of disability as compared to the actual level of physical activity (PAL) in patients with sub-acute back pain.

Methods: Patients with 4-7 weeks of non-specific low back pain (LBP) participated in this study. Their habitual physical activity level before the back pain started (H-PAL), their actual level of physical activity (PAL) and their perceived decline in the level of physical activity after the onset of pain (PAD) were assessed. The association between these physical activity related variables and perceived disability (QBPDS), fear of movement/(re)injury (TSK), pain catastrophizing (PCS) and pain intensity (VAS) was examined. The role of PAD as a mediator in the association between fear of movement/(re)injury and disability was examined by three linear regression analyses.

Results: 123 patients (66 male and 57 female) with a mean age of 44.1 years ( $\mathrm{SD}=10.3)$ participated in this study. PAD was significantly correlated with disability, fear of movement/(re)injury, pain catastrophizing and pain intensity. PAD and PAL appeared more important in the explanation of disability in the subgroup of patients who were physically active before their back pain started. Generally, PAD indeed mediated the association between fear of movement/(re)injury and disability.

Conclusions: The perceived decline in physical activity, rather than the current physical activity itself is important in the evaluation of the impact of activity related changes on disability in low back pain.

(C) 2004 Published by Elsevier Ltd on behalf of European Federation of Chapters of the International Association for the Study of Pain.
\end{abstract}

Keywords: Physical activity; Pain-related fear; Disability; Low back pain

\footnotetext{
* Corresponding author. Tel.: +31 45 5282226; fax: +31 455282000.

E-mail address: j.verbunt@srl.nl (J.A. Verbunt).
}

\section{Introduction}

Activity intolerance is a problem which is often reported by patients with chronic low back pain (CLBP). As a result of their back pain, they perceive a disabling 
reduction of their level of physical activity. Fear of movement/(re)injury has been reported to be strongly associated with activity limitations, often stronger than pain severity (Vlaeyen et al., 1995a; Crombez et al., 1999). The fear-avoidance model predicts that when patients with an acute back pain problem, interpret their pain as threatening (they catastrophize about their pain), fear of movement/(re)injury emerges. The expectation of adverse consequences of increasing their physical activity level ("I may end up in a wheelchair") may be the reason to avoid physical activities. In the long run, long-lasting avoidance behaviour can result in both disability and disuse. The latter has been defined as performing at a reduced level of physical activity in daily life (Verbunt et al., 2003).

In contrast to the influence of pain-related fear on the perceived disability level, which has been reported frequently (Vlaeyen et al., 1995a; Klenerman et al., 1995; Mc Cracken et al., 1996; Crombez et al., 1999; Linton, 2000; Fritz et al., 2001) the presumed negative influence of pain-related fear on the actual level of physical activity in daily life (PAL) and accompanying disuse has received less attention in pain literature. In this area, most studies have focused on the difference between the PAL or physical fitness level of patients with CLBP as compared to those of healthy individuals. Moreover, these studies are equivocal, and reveal that levels of PAL or physical fitness for patients with CLBP were either lower (Schmidt, 1985; Davis et al., 1992; Brennan et al., 1987; Van der Velde and Mierau, 2000; Nielens and Plaghki, 2001) or comparable (Battie et al., 1989; Hurri et al., 1991; Kellet et al., 1991; Protas, 1999; Wittink et al., 2000; Verbunt et al., 2001) to scores of healthy subjects. Based on these data, the conclusion seems justified that physical activity plays a rather limited role in the explanation of disability of CLBP patients. Some authors have even questioned the presence of disuse or physical deconditioning in patients with CLBP (e.g., Wittink et al., 2000).

However, if patients report activity intolerance and associated disability, it is unlikely that they compare their PAL to the PAL of others. It seems more likely that their evaluation is based on a comparison between their actual PAL in reference to their habitual PAL before their back pain started. In making such a comparison, their judgement is likely to be based on a perceived decline in the level of their daily activities (PAD = perceived physical activity decline) rather than on their actual PAL. This would imply that PAD, would be more strongly associated with self-reported disability than PAL. Therefore, research on the role of physical activity and disability in back pain, might benefit from the assessment of the individual's decline in the level of physical activity over time (PAD) as a reaction on a pain problem instead of his or her actual level of physical activity. Until now, however, only the latter has been the subject of research in most studies. In contrast to former studies, in the current study we will therefore focus on the disabling role of PAD.

According to the fear-avoidance model, fearful patients will avoid physical activities which are expected to produce adverse consequences when performed. Such avoidance behaviour can then result in a PAD, leading to a higher interference in daily life activities and participation, and in the long run to physical deconditioning. Following this line of reasoning, PAD would act as a mediator in the association between fear of movement/ (re)injury and disability. If the association between fear of movement/(re)injury and PAD can be demonstrated, this will also underscore the potential role of physical deconditioning as a long term consequence of fear of movement as suggested by the fear-avoidance model. As we know from research in exercise physiology in healthy individuals, a decline in one's level of PAL might result in a worsening of physical deconditioning; including changes in aerobic fitness, muscle strength, muscle coordination and weight (Convertino et al., 1997), it can be hypothesized that PAD is also related to fitness related changes as a result of back pain.

It is also important to consider that not all patients with CLBP report activity limitations. PAD is not the only factor causing disability in back pain. It can be hypothesized that activity-related limitations can probably be more disabling for patients who were used to an active lifestyle before their back pain started as compared to formerly sedentary patients. Simply because they used to perform more activities, more activities can be limited, resulting in more influence on a patients daily activity schedule. In this study, a discrepancy between the role of PAD in active as compared to sedentary patients will be studied.

In view of the above mentioned, in this study three hypotheses will be tested:

1. A perceived decline in the level of physical activity (PAD) is more strongly associated with the level of perceived disability than the actual level of physical activity (PAL).

2. A perceived decline in the level of physical activity (PAD) plays a mediating role in both the association between fear of movement/(re)injury and disability.

3. The disabling role of a perceived decline in the level of physical activity (PAD) is more pronounced in patients with a formerly active lifestyle as compared to formerly sedentary patients.

\section{Methods}

\subsection{Patients}

In this study, 123 patients, with sub-acute low back pain participated. Pain was localised below the scapulae 
and above the gluteal folds (following IASP taxonomy) (Merskey and Bogduk, 1994). At the moment of inclusion, patients suffered low back pain for 4-7 weeks (sub-acute phase) due to either a first or new episode of pain. In the last three months previous to the actual episode started, they had no significant activity limitations due to back pain. Additional selection criteria were (1) age between 18 and 60 years and (2) sufficient knowledge of the Dutch language. Patients, who (3) had a specific cause or strong suspicion of a specific cause, such as lumbar disc herniation with neurological complications, major structural back abnormality, evidence of inflammatory, systemic or neoplastic disease, (4) were pregnant, (5) had a major psychiatric illness, (6) suffered from a muscle disease, or (7) had a cardiac pacemaker, were excluded from the study. Patients were recruited in two different ways: they were referred by their general practitioner or they responded to an advertisement in a local newspaper. Selection criteria were either checked by the referring general practitioner or, when a patient replied on the advertisement, criteria were checked by a physician in rehabilitation medicine. Both physicians performed a medical screening according the low back pain guideline of the Dutch Society of General Practitioners (Faas et al., 1996). All patients gave their written informed consent to participate in the study. The experimental protocol was approved by the Medical Ethics Committee of the Rehabilitation Foundation Limburg and the Institute for Rehabilitation Research, Hoensbroek, the Netherlands.

\section{Measures}

\subsection{Physical activity}

\subsubsection{Physical activity in daily life before the onset of pain/habitual PAL (H-PAL)}

To score the habitual physical activity level, which reflects the level of daily life activities before the back pain started, the Baecke Physical Activity Questionnaire (BPAQ) was used.

To be able to score activities in the past, the BPAQ was transformed in the past tense. Patients had to recall their physical activity level during the last year before the back pain started. The BPAQ consists of three indices of habitual physical activity : the occupational activity index; sport activity index and the leisure time activity index. The reliability (Baecke et al., 1982) and validity (Philippaerts et al., 1999) of the questionnaire in a healthy population appear to be good. The BPAQ is a reliable instrument to measure habitual PAL in patients with CLBP (Jacob et al., 2001).
3.1.2. Physical activity in daily life after the onset of pain (PAL)

To measure PAL a triaxial accelerometer (RT3; Stayhealthy Inc., Monrovia, USA); consisting of three uniaxial piezo-resistive accelerometers was used to record the amount of body movement. Acceleration signals from the three measurement directions (the posterior, the mediolateral and the longitudinal axes of the trunk) were amplified and filtered. The rectified and integrated acceleration from all three directions over a time-period of $1 \mathrm{~min}$ was calculated. The number of occasions on which this signal exceeded a predefined threshold was calculated. The data is the output of the accelerometer, measuring the intensity of physical activities and was expressed in counts per minute. Data collection continued uninterrupted for seven days. Output was stored in a data memory chip within the accelerometer and was read out by a computer after one week. Patients attached the RT3 with a clip on their waist. They were instructed to wear the RT3 during waking hours, for seven days except during bathing, taking a shower or swimming. In addition, they recorded in a diary the moment of attaching the RT3 to the body in the morning and the moment of taking it off in the evening. In case they had to remove the RT3 during the day, the reason and the exact time-period had to be registered also. Physical activity in daily life was expressed as the total sum of counts registered per day. The triaxial accelerometer is a valid instrument for the measurement of physical activity in daily life in patients with CLBP (Verbunt et al., 2001).

\subsubsection{Perceived physical activity decline}

For the measurement of perceived physical activity decline (PAD), 20 different regular daily activities were presented. The presented activities were derived from the PARS (Physical Activity Rating Scale; Vercoulen et al., 1997). For each activity, patients were asked to indicate how frequently they had performed the specified activity in the last two weeks using the following response categories: never, rarely, now and then, often and very often. Examples of activities are: $1 \mathrm{~h}$ walking, $4 \mathrm{~h}$ working, climbing two stairs and one hour shopping. After they rated their activity level per item, patients were asked if they would have performed this specific activity more often if they would not have back pain. If the answer was yes for a specific item, one point was counted. On the contrary if the answer was no, the score on that item was zero. The total sum score for 20 activities resulted in a score for PAD; a perceived decline in the level of physical activity after the onset of pain as perceived by the patient, with a theoretical range in PAD of 0-20. Internal consistency of PAD appeared to be adequate (Cronbach's alpha $=0.92)$. 


\subsubsection{Muscle strength}

Muscle strength, one of the components of physical fitness, was measured as isometric muscle strength of the quadriceps muscle using a Cybex (Cybex II isokinetic dynamometer, Cybex, Ronkonkoma, NY) according to the protocol as described by Verbunt et al. (2003, 2005). Muscle strength was measured as the maximum isometric peak torque $(T)$ of two efforts. Torque was standardised to torque per kilogram lean body mass (lean body mass was calculated as weight - (percentage of body fat $/ 100 *$ weight)). Calculations of the percentage of body fat were performed based on a sum of four subcutaneous fat folds according the procedure of Durnin and Womersly (1974). Fat folds were measured with a Servier skinfold calliper (Biersteker et al., 1983). To control for submaximal performance, the interpolated twitch technique was used during muscle strength testing (Rutherford et al., 1986). Signal analysis was performed off-line using MATLAB software (The Math Works Inc., Natick, Mass).

\subsection{Pain}

\subsubsection{Pain intensity}

Current pain intensity was rated on a visual analogue scale (VAS) with extremes of 0 (no pain) and 100 (unbearable pain) (Bolton, 1999).

\subsubsection{Pain related disability}

Low back pain disability was assessed using the Quebec Back Pain Disability Scale (QBPDS). The QBPDS contains 20 items. Each item is scored from 0 (no difficulty performing this activity) to 5 (Impossible to perform this activity) and the final QBPDS score is expressed with a higher number indicating greater disability. The QBPDS is a valid and reliable measure for low back disability both in the original version (Kopec et al., 1995), as well as in the Dutch version (Schoppink et al., 1996).

\subsection{Psychological characteristics}

\subsubsection{Fear of movement/(re)injury}

The Tampa scale for Kinesiophobia (TSK) is a 17item questionnaire aimed at the assessment of fear of movement/(re)injury. The Dutch version of the TSK has been reported to be reliable and valid (Vlaeyen et al., 1995b; Goubert et al., 2000).

\subsubsection{Depression}

The Dutch version of the Beck Depression Inventory (BDI) measures depression. It is a 21-item self-report questionnaire designed to measure the severity of depression and was proposed by the Dutch Committee for the Standardization of Depression Questionnaires (Beck et al., 1979; Zitman et al., 1989).

\subsection{Statistical analyses}

Spearman rank correlation coefficients were calculated to examine the association between pain disability and physical activity related variables. Since in functional performance gender and age are important characteristics, for the association between activity related variables and muscle strength, a partial correlation coefficient was used, corrected for age and gender. Results for groups were expressed as a mean score and standard deviation combined with the range of scores. Comparisons between two groups were performed using the Student's $t$-test for unpaired observations in case of a normal distribution of the data $(\alpha=0.05)$. In case of a non-normal distributions of the data the Mann-Whitney $U$ test for unpaired observations was used.

To evaluate the role of perceived PAD as a mediator in the relation of fear of movement/(re)injury and disability three linear regression analyses were performed according to Baron and Kenny (1986). In the first analysis disability was the dependent variable and gender, age, pain intensity and fear of movement/(re)injury were the independent variables. In the second analysis, PAD was introduced as dependent variable and the independent variables were identical to those in the first analysis. In the third analysis disability was again the dependent variable in the equation and PAD was added to the set of independent variables. If PAD acts as a mediator in the relation fear of movement/(re)injury and disability, the contribution of fear of movement/ (re)injury in the first and the second model should be statistically significant, whereas its influence should decrease in the third model after the introduction of PAD. Since the data were collected in a cross sectional design, hypothetical inverse relations were also tested. Again with the three regression analyses as presented above, it was checked whether disability acted as a mediator in the relation between fear of movement/(re)injury and PAD and whether fear of movement/(re)injury acted as a mediator in the association between PAD and disability.

To evaluate whether the role of PAD in the explanation of disability differed in patients with a sedentary lifestyle as compared to patients with an active lifestyle, patients were categorized in two groups based on the median split of their Baecke score. In both groups a linear regression analysis was performed to identify variables significantly contributing to the explanation of disability. Independent variables were pain intensity, depression, PAD and PAL.

For all linear regression analyses standardized beta coefficients and their significance were tested under the null hypothesis that the coefficient differed from zero. To control for co-linearity, variable inflation factors (VIF) were checked and had to be below 10. Outliers, if any, with a Cook distance above 1 were removed from 
the model. All statistical analyses were performed using SPSS software (SPSS Inc., Chicago, Ill).

\section{Results}

\subsection{Demographic and pain related characteristics}

This study included 123 patients (66 male and 57 female) with a mean age of 44.1 years $(S D=10.3)$. Main characteristics of the current pain episode were: a sudden onset of the pain was reported by $50 \%$, radiating pain into the legs by $68 \%$, and an earlier episode of back pain by $76 \%$ of the participants. Mean duration of complaints on the day of measurement was 38.5 days $(\mathrm{SD}=8.3)$. Eighteen of the 86 patients with a paid job $(21 \%)$ were still on sick leave at the time of measurement. Mean pain intensity was $42.1(\mathrm{SD}=21.9)$, with no gender differences. Mean TSK score for all patients was $36.0(\mathrm{SD}=7.4)$. On average men had a significantly

Table 1

Pain disability and physical activity related variables (Spearman rank correlation coefficients are presented)

\begin{tabular}{lccr}
\hline & H-PAL & PAD & PAL \\
\hline Pain disability related variables & & \\
Disability & -0.10 & $0.47^{* *}$ & -0.19 \\
Fear of injury & 0.06 & $0.34^{* *}$ & 0.06 \\
Depression & -0.02 & $0.30^{* *}$ & -0.17 \\
Pain intensity & -0.02 & $0.27^{* *}$ & 0.07 \\
Physical activity related variables & & \\
Muscle strength & & & \\
H-PAL & 0.15 & -0.17 & 0.20 \\
PAD & - & 0.18 & $0.25^{*}$ \\
\hline
\end{tabular}

H-PAL, physical activity in daily life before the onset of pain (habitual PAL); PAL, physical activity in daily life after the onset of pain.

${ }^{a}$ Partial correlation coefficients corrected for age and gender are presented.

${ }^{* *} p<0.05$. higher TSK scores of $(M=37.2 ; \mathrm{SD}=6.9)$ as compared to women $(M=34.5 ; \mathrm{SD}=7.8 ; p=0.05)$. The mean score for BDI was $7.5(\mathrm{SD}=5.5)$.

\subsection{Physical activity}

Mean BPAQ scores of male and female patients were $8.50(\mathrm{SD}=1.40)$ and $8.27(\mathrm{SD}=1.14)$, respectively. These scores were comparable with scores of healthy Dutch individuals, with $M=8.2 \quad(\mathrm{sem}=0.1)$ and $M=8.4(\mathrm{sem}=0.1)$ for males and females, respectively (Baecke et al., 1982). This would imply that the persons in this study were, before their back pain started, as active as a general Dutch population. As to physical fitness-related characteristics in this sub-acute phase of back pain, on average male patients scored $2.44 \mathrm{~N}$ $\mathrm{m} / \mathrm{kg}(\mathrm{SD}=0.98)$ on the muscle strength test. They weighed $83.4 \mathrm{~kg}(\mathrm{SD}=15.6)$ and their mean height was $1.79(\mathrm{SD}=0.06) \mathrm{m}$. Men had a mean percentage of body fat of $23.8(\mathrm{SD}=5.7)$. The mean score of women on the muscle strength test was $2.01 \mathrm{~N} \mathrm{~m} / \mathrm{kg}$ $(\mathrm{SD}=0.75)$. They had a mean weight of $72.7 \mathrm{~kg}$ $(\mathrm{SD}=15.0)$ and a mean height of $1.68(\mathrm{SD}=0.11)$. Their mean percentage of body fat was 37.2 $(\mathrm{SD}=5.3)$. Table 1 displays the associations between physical activity related variables (H-PAL, PAD and PAL) and pain disability related variables using spearman rank correlation coefficients. Habitual PAL (H-PAL) did not relate significantly to any of the pain disability related variables. In contrast, PAD was significantly associated with disability, fear of injury, catastrophizing, depression and pain intensity. PAL was only interrelated with H-PAL. No relations with disability related variables were found.

\section{3. $P A D$ as a mediator}

In Table 2 results of three linear regression analyses are presented. For all analyses VIFs were low (with a

Table 2

PAD as a mediator in the relation fear of injury and disability

\begin{tabular}{|c|c|c|c|c|c|}
\hline Dependent variable & Independent variables & $R^{2}$ & Adj $R^{2}$ & Standardized $\beta$ & $p$-Value \\
\hline \multirow[t]{4}{*}{ Disability } & Gender & 0.46 & 0.44 & -0.08 & 0.24 \\
\hline & Age & & & 0.14 & 0.04 \\
\hline & Pain intensity & & & 0.57 & $<0.01$ \\
\hline & Fear of injury & & & 0.19 & 0.01 \\
\hline \multirow[t]{4}{*}{ Physical activity decline (PAD) } & Gender & 0.22 & 0.20 & -0.20 & 0.02 \\
\hline & Age & & & -0.04 & 0.65 \\
\hline & Pain intensity & & & 0.20 & 0.03 \\
\hline & Fear of injury & & & 0.38 & $<0.01$ \\
\hline \multirow[t]{5}{*}{ Disability } & Gender & 0.48 & 0.46 & -0.05 & 0.46 \\
\hline & Age & & & 0.15 & 0.04 \\
\hline & Pain intensity & & & 0.52 & $<0.01$ \\
\hline & Fear of injury & & & 0.10 & 0.19 \\
\hline & PAD & & & 0.23 & $<0.01$ \\
\hline
\end{tabular}


maximum of 1.324 in the third analysis) suggesting that there is no problem of colinearity. In all analyses, Cook's distances did not exceed 1 . In the first analysis with disability as a dependent variable the percentage of explained variance appeared to be $44 \%$. In the first model pain intensity proved to be an important variable (standardized $\beta=0.57$ ) in the explanation of disability. But also fear of movement/(re)injury contributed significantly with a standardized $\beta$ of 0.19 . In the second analysis, in which PAD was introduced as the dependent variable, $19.5 \%$ of the variance in PAD could significantly be explained. Fear of movement/(re)injury was the most important variable in the explanation of PAD, with a standardized $\beta$ of 0.38 . In the third model, disability was the dependent variable, which was in accordance with the first model. PAD was introduced as an independent variable in the equation. $46 \%$ of the variance in disability could be explained by this model, but after the introduction of PAD, fear of movement/ (re)injury no longer contributed significantly. In the analyses focussing on an inverse association, where disability was tested as a mediator in the association between fear of movement/(re)injury and PAD, fear of movement/(re)injury showed a significant contribution to the explanation of PAD, which lasted after the introduction of disability in the model. Also in the analyses on the mediating role of fear of movement/(re)injury in the association between PAD and disability, the significant contribution of PAD to the explanation of disability lasted after the introduction of fear of movement/(re)injury in the model. In other words, support was exclusively found for the mediating role of PAD in the association between fear of movement/(re)injury and disability, but not for other mediation models.

\subsection{Lifestyle related differences}

In Table 3, activity related scores of formerly sedentary and formerly active patients are presented. Groups were categorized based on the median split of their Bae-

Table 3

Mean scores on activity related variables for patients with an active lifestyle as compared to patients with a formerly sedentary lifestyle

\begin{tabular}{lllr}
\hline & $\begin{array}{l}\text { Sedentary } \\
(\text { H-PAL } \leqslant 8.4)\end{array}$ & $\begin{array}{l}\text { Active } \\
(\text { H-PAL }>8.4)\end{array}$ & $p$-Value \\
\hline H-PAL & $7.4 \pm 0.8(5.8-8.3)$ & $9.4 \pm 0.9(8.4-12)$ & $<0.01$ \\
PAD $^{\mathrm{a}}$ & $3.1(0-17)$ & $5.6(0-20)$ & 0.13 \\
PAL & $191,812 \pm 72,894$ & $216,973 \pm 84,715$ & 0.28 \\
& $(59,893-360,803)$ & $(88,945-436,986)$ & \\
Disability & $40.3 \pm 19.1(1-83)$ & $38.6 \pm 16.7(3-72)$ & 0.63 \\
\hline
\end{tabular}

Values are means \pm SD and ranges. H-PAL, habitual PAL; physical activity level before the pain started. PAL, physical activity level after the onset of pain.

${ }^{a}$ As PAD was not normally distributed the median score combined with ranges is presented.
Table 4

Linear regression analysis with disability as dependent variable in two groups based on the median split of H-PAL (Baecke)

\begin{tabular}{lllllr}
\hline $\begin{array}{l}\text { Dependent } \\
\text { variable }\end{array}$ & $\begin{array}{l}\text { Independent } \\
\text { variables }\end{array}$ & $R^{2}$ & Adj $R^{2}$ & $\begin{array}{l}\text { Standardized } \\
\beta\end{array}$ & $p$-Value \\
\hline $\begin{array}{l}\text { Sedentary (H-PAL } \leqslant 8.4) \\
\text { Disability }\end{array} \quad$ & & & & \\
& Pain intensity & 0.57 & 0.52 & 0.64 & $<0.01$ \\
& Depression & & & 0.24 & 0.04 \\
& PAD & & & 0.07 & 0.55 \\
PAL & & & -0.16 & 0.16 \\
Active (H-PAL $>$ 8.4) & & & & \\
Disability $\quad$ Pain intensity & 0.47 & 0.42 & 0.48 & $<0.01$ \\
& Depression & & & 0.06 & 0.55 \\
& PAD & & & 0.33 & 0.02 \\
& PAL & & & -0.28 & 0.02 \\
\hline
\end{tabular}

H-PAL, physical activity level before onset of pain; PAL, physical activity level after the onset of pain; PAD, decline in the level of physical activity.

cke-score (H-PAL), which was 8.4. In Table 4, results of regression analyses indicated that in the sedentary group $52 \%$ of the variance could be explained by the model. VIFs ranged from 1.088 to 1.158 showing that there was no colinearity. Both PAD and PAL did not significantly contribute to the explanation of disability. In the active group the percentage explained variance was $42 \%$. In contrary to the sedentary group, in patients who were active before their back pain started, both PAD and PAL contributed significantly in the explanation of disability.

\subsection{Error analysis}

Twelve patients $(10 \%)$ had an invalid score on PAL and their score was not used in the calculations. Their registered period of physical activity in daily life as measured with the RT3 was less than 5 days, which was the minimum time period acceptable to express PAL (Gretebeck and Montoye, 1992). This deficient data registration of PAL was most of the time based on insufficient battery charge of the RT3. $16 \%$ of all patients had an incomplete score for H-PAL. For these patients the total Baecke score could not be calculated. Most incomplete Beacke scores (16 of 20) were based on the absence of the work-index, which is an essential part to calculate the total Baecke score. 14 persons of the 16 with an incomplete work-index score were women with full time house keeping activities. They did not significantly differ in age, disability level, level of physical activity or physical performance compared to women with full time housekeeping who had a complete work-index.

\section{Discussion}

In this sample of sub acute low back pain patients PAD was significantly related to disability. In addition, 
PAD acted as a mediator in the relation between fear of movement/(re)injury and disability. It appeared that for patients with an active lifestyle before the pain started, PAD was significantly contributing to the explanation of disability, whereas this was not the case for patients with a formerly sedentary lifestyle.

\subsection{PAD as a mediator}

Based on Table 1 it appeared that disability related variables were related to PAD and not to H-PAL and PAL. These data support the hypothesis that changes in the level of physical activity are more disabling then the actual level of physical activity.

Fearful patients with sub-acute back pain, experience a fear-induced activity decline, which they perceive as disabling. The apparent interrelation of fear of injury, a change in physical activity and disability could also be suggested based on the results of a study on graded exposure in chronic pain (Vlaeyen et al., 2002). In this study improvements in pain-related fear and pain catastrophizing were shown, based on exposure in vivo. The results, measured over a short term, showed a decrease in disability and an increase in PAL as assessed by accelerometry. This rapid increase in activity seems to support the role of behavioural factors in changes in activity levels in pain. Because, if PAL was limited by physiological factors (like physical deconditioning), changes in PAL would not be expected on such a short term. Based on the results of our study, it can be hypothesized that for an optimal result of graded exposure in vivo, expressed as a high increase in PAL after treatment, not only fear of injury, but also PAD can be taken into account in the selection of patients.

Pain intensity appeared to be the most disabling factor in patients with sub-acute LBP. This important role for pain intensity in the first phase of LBP was already reported by others (Sieben et al., 2002; Fritz et al., 2001). In the study of Sieben et al. in patients with acute back pain, pain intensity was, in accordance with our findings, even more important than fear of movement/ (re)injury in the explanation of disability. However, in the explanation of PAD, pain intensity seemed less important as compared to pain-related fear. In a subacute phase of back pain, the disabling role of pain intensity is therefore probably less based on a pain induced activity decline, but will mainly be based on other mechanisms. It is however beyond the scope of this article to explore this alternative routes of the influence of pain intensity on the level of perceived disability in patients with sub-acute low back pain.

\subsection{The disabling role of $P A D$ and $P A L$}

The levels of perceived disability for both formerly active and formerly sedentary patients were comparable.
However, in the explanation of disability, PAD and PAL seemed important factors in patients with a formerly active lifestyle, but they did not contribute in formerly sedentary patients. In the active group, even after correction for the actual level of activities (PAL), PAD was still significantly related to disability. Also PAL was significantly related to disability. This disabling effect of activity is even more interesting, given the fact that the mean PAL for the active group was still higher (although not significant) as compared to the formerly sedentary group. In contrast, for patients with a sedentary lifestyle before the pain started the impact of both PAD and PAL seemed less important in the explanation of disability. Although this pain episode has an impact on their daily life, since they report a level of disability comparable to the active group, their daily physical activity schedule is probably less influenced after the onset of pain. Other factors, such as depression and pain intensity appeared to be more disabling. Also important to consider in the evaluation of the disabling role of PAD, is the fact that PAD did not show a significant association with H-PAL. Patients, who were more physically active before their pain started, did not necessarily show a higher decline in activity level and patients who had a more sedentary lifestyle before their pain started, did not necessarily have a lower decline. This finding argues the suggestion that the non-disabling role of PAD in the sedentary group could be based on a floor effect in PAD. In conclusion, for patients with a formerly active lifestyle both PAD and PAL seemed more disabling as compared to patients with a formerly sedentary lifestyle.

This discrepancy in both activity groups in the association between a disability related PAD and the actual level of PAL is important to consider in both clinical practice and research. Regarding clinical practice, for patients with a formerly active lifestyle, having pain interfered more with their physical activity schedule. Although they probably report disabling activity limitations, PAL or the level of physical fitness, will not necessarily be low as compared to the mean levels of the population. On the other hand, sedentary patients will probably report a disabling pain instead of activity limitations, even though their PAL and level of physical fitness is probably low as compared to the mean level of the population. In research, this discrepancy between the reported reason for disability and the actual PAL or level of physical fitness could be an explanation for the absence of an evident association between disability and PAL or disability and physical fitness, which appeared in studies in a cross sectional design (Wittink et al., 2000; Verbunt et al., 2001).

\subsection{PAD and disability}

Although the constructs of PAD and disability share many similarities, the data of the sedentary group, as 
presented in Table 4, indicated already, that these constructs are not identical. PAD is not related to disability in this model. Disability has been defined by the World Health Organization (1980) as any restriction or lack of ability to perform an activity in the manner or within the range considered normal for a human being (1980). Pain-related disability questionnaires focus therefore on both a decrease in capacity in the performance and altered performance of regular activities of daily living in patients with pain. PAD is defined as a decrease in the level of physical activity relative to a person's activity level before the onset of pain as perceived by the patient. PAD is therefore only focused on an individual change in the intensity of PAL. If, for example, an activity can still be performed despite great difficulties due to back pain, this will influence a disability score but will not influence PAD. Compromised performance of an activity can be disabling but does not necessarily influence PAD.

\subsection{Methodological issues}

In this study H-PAL and PAL, although they both represent a physical activity level, were measured using different assessment methods. H-PAL was based on self report (Baecke questionnaire), whereas PAL was obtained by accelerometry. In research on chronic pain, the use of objective methods to measure physical activity instead of self-report is advised in order to avoid the influence of a patients' perception or interpretation of the variable of interest, which can harm test validity (Verbunt et al., 2001). However, information on physical activities as performed in the past can only be obtained based on self-report. In order to measure activities before the back pain started, the Baecke questionnaire was translated in the past tense. To reduce the influence of information bias, the interval between the moment of measurement and the time period the Baecke questionnaire was aimed at (i.e., one year before the back pain started), was chosen to be only 4-7 weeks. As H-PAL, also PAD was based on self-report. At this moment, no other assessment method for measuring activity decline is available. However, when in future research the inter-correlation between Beacke and the accelerometer (RT3) is found to be high, computation of PAD scores based on the substraction of Z-scores of Baecke-Z-score of PAL might be an option. In healthy subjects, Philippaerts et al. (1999) found that the Baecke questionnaire correlated well with the Tracmor accelerometer, which like the RT3, is a triaxial accelerometer. However, similar findings in a patient sample is lacking.

This study was based on a cross-sectional design, which implies that the possibility to collect information on causal relationships is limited. Therefore besides the mediating role of PAD in the association fear of move- ment/(re)injury and disability, also two other associations between the three variables were checked. Firstly it was checked whether disability acted as a mediator in the association between fear of movement/(re)injury and secondly if fear acted as a mediator in the relation PAD and disability. In both analyses, no mediating role for either disability or fear of injury was found, which strengthen the finding that PAD had a mediating role in the association between fear and disability.

\subsection{Muscle strength}

This study was mainly focussed on PAL and the disabling effect of changes in PAL. But based on the fact that a decrease in one's level of physical activity in daily life leads to physical deconditioning, it can be hypothesized that PAD is also associated with reduced fitness. In this study, muscle strength, which is one of the components of physical fitness, showed no relation with the actual level of physical activity nor with a decline in activities. In common with the observations of PAD, changes (decline) in muscle strength may be more important than actual levels of muscle strength in determining disability. At the present, a longitudinal study covering a period of one year after the acute onset of pain, originating from the present study, is underway, investigating fitness related changes and their association with disability. Knowledge on this association would open the prospect for more patient specified interventions directed towards positive changes in disability and physical activity.

Summarizing, in this study a decline in the level of physical activities seemed more disabling as compared to the actual level of activities. An activity decline appeared to play a mediating role in both the association between fear of movement/(re)injury and disability. Both the level of physical activity and a decline in activity seemed more important in the explanation of disability in patients with an active lifestyle before their back pain started as compared with patients with a formerly sedentary lifestyle. Research on the disabling role of physical activity restrictions in back pain should be focussed on PAD instead of PAL.

\section{Acknowledgements}

The authors thank Sita van Riet and Piet Portegijs for their cooperation in the inclusion of patients in this study and the participating general practitioners for the reference of the patients. They also want to thank the Department of Movements Sciences of the Maastricht University for the use of the Cybex-equipment in their laboratory. This study was supported by the Council for Medical and Health Research of the Netherlands 
(NWO-MW), Grant No. 904-65-090 and Zorgonderzoek Nederland (ZON) Grant No. 96-06-006.

\section{References}

Baecke JA, Burema J, Frijters JE. A short questionnaire for the measurement of habitual physical activity in epidemiological studies. Am J Clin Nutr 1982;36:936-42.

Baron RM, Kenny DA. The moderator-mediator variable distinction in social psychological research: conceptual, strategic, and statistical considerations. J Personality Social Psychol 1986;51:1173-82.

Battie M, Bigos SJ, Fisher LD, Hansson TH, Nachemson AL, Spengler DM, et al. A prospective study of the role of cardiovascular risk factors and fitness in industrial back pain complaints. Spine 1989;14:141-7.

Beck AT, Rush AJ, Shaw BF, Emmery G. Cognitive therapy of depression. New York: John Wiley; 1979.

Biersteker MWA, Broere F, Biersteker PA. Het schatten van een gewichtspercentage lichaamsvet met eenvoudige hulpmiddelen. Geneeskunde en Sport 1983;16:29-32.

Bolton JE. Accuracy of recall of usual pain intensity in back pain patients. Pain 1999;533-539.

Brennan GP, Ruhling RO, Hood RS, et al. Physical characteristics of patients with herniated intervertebral lumbar discs. Spine 1987;12:699-702.

Convertino VA, Bloomfield SA, Greenleaf JF. An overview of the issues: physiological effects of bed rest and restricted activity. Med Sci Sports Exerc 1997;29:187-90.

Crombez G, Vlaeyen JWS, Heuts PHTG, Lysens R. Fear of pain is more disabling than pain itself. Evidence on the role of pain-related fear in chronic back pain disability. Pain 1999;80:329-40.

Davis VP, Fillingin RB, Doleys DM, Davis MP. Assessment of aerobic power in chronic pain patients before and after a multi-disciplinary treatment program. Arch Phys Med Rehabil 1992;73:726-9.

Durnin JGVA, Womersly J. Body fat assessed from total body density and its estimation from skinfold thickness: measurements on 481 mean and women aged 16 to 72 years. Brit J Nutr 1974;32:77-97.

Faas A, Chavannes AW, Koes AW, Van den Hoogen JMM, Mens JMA, Smeele I, et al. Practice guideline "low back pain" (translation). Utrecht; 1996.

Fritz JM, George SZ, Delitto A. The role of fear-avoidance beliefs in acute low back pain: relationships with current and future disability and work status. Pain 2001;94:7-15.

Goubert L, Crombez G, Vlaeyen JWS, Van Damme S, Van den Broeck A, Van Houdenhove B. De Tampa schaal voor Kinesiofobie: psychometrische karakteristieken en normering [The Tampa scale for Kinesiophoba: psychometric properties and norms]. Gedrag en Gezondheid 2000;28:54-62.

Gretebeck RJ, Montoye HJ. Variability of some objective measures of physical activity. Med Sci Sports Exerc 1992;24:1167-72.

Hurri H, Mellin G, Korhonen O, Harjula R, Harkapaa K, Luamo J. Aerobic capacity among chronic low back pain patients. J Spinal Disord 1991;4:34-8.

Jacob T, Baras M, Zeev A, Epstein L. Low back pain: reliability of a set of pain measurement tools. Arch Phys Med Rehabil 2001;82:735-42.

Kellett KM, Kellett DA, Nordholm LA. Effects of an exercise program on sick leave due to back pain. Phys Ther 1991;71:283-90.

Klenerman L, Slade PD, Stanley IM, Pennie B, Reilly JP, Atchison LE, et al. The prediction of chronicity in patients with an acute attack of low back pain in a general practice setting. Spine 1995;20:478-84.

Kopec J, Esdaile J, Abrahamowitz M, Abenhaim L, Wood-Dauphines $\mathrm{S}$, Lamping $\mathrm{D}$, et al. The Quebec back pain disability scale. Measurement properties. Spine 1995;20(3):341-52.
Linton SJ. A review of psychological risk factors in back and neck pain. Spine 2000;25(9):1148-56.

McCracken LM, Gross RT, Aikens J, Carnkike JCLM. The assessment of anxiety and fear in persons with chronic pain: a comparison of instruments. Behav Res Ther 1996;34:927-33.

Merskey H, Bogduk N. Classification of chronic pain. Second edition, IASP Task force on taxonomy. Seattle: ASP Press; 1994.

Nielens H, Plaghki L. Cardiorespiratory fitness, physical activity level, and chronic pain: are men more affected than women. Clin J Pain 2001;17:129-37.

Philippaerts RM, Westerterp KR, Lefevre J. Doubly labelled water validation of three physical activity questionnaires. Int J Sports Med 1999;20(5):284-9.

Protas EJ. Physical activity and low back pain. In: Mitchell M et al., editors. Pain 1999 an updated review; refresher course syllabus, 9th World Congress on Pain. Seattle: IASP Press; 1999. p. 145-52.

Rutherford OM, Jones DA, Newham DJ. Clinical experimental application of the percutaneous twitch superimposition technique for the study of human muscle activation. J Neurol Neurosurg Psychiat 1986;49:1288-91.

Schoppink LM, van Tulder MW, Koes BW, Beurskens AJ, de Bie RA. Reliability and validity of the Dutch adaptation of the Quebec back pain disability scale. Phys Ther 1996;76:268-75.

Schmidt AJ. Performance level of chronic low back pain patients in different treadmill test conditions. J Psychosom Res 1985;29:639-45.

Sieben JM, Vlaeyen JW, Tuerlinkx S, Portegijs PJ. Pain-related fear in acute low back pain: the first two weeks of a new episode. Eur $\mathbf{J}$ Pain 2002;6(3):229-37.

van der Velde G, Mierau D. The effect of exercise on percentile rank aerobic capacity, pain, and self-rated disability in patients with chronic low back pain: a retrospective chart review. Arch Phys Med Rehabil 2000;81:1457-63.

Verbunt J, Westerterp K, van der Heijden G, Seelen H, Vlaeyen $\mathrm{J}$, Knottnerus A. Physical activity in daily life in patients with chronic low back pain. Arch Phys Med Rehabil 2001;82:726-30

Verbunt JA, Seelen HA, Vlaeyen JW, van der Heijden GJ, Heuts PH, Pons K, et al. Disuse and deconditioning in chronic low back pain; concepts and hypotheses on contributing mechanisms. Eur J Pain 2003;7:9-21.

Verbunt JA, Seelen HA, Vlaeyen JW, Bousema EJ, van der Heijden GJ, Heuts PH, Knottnerus JA. Pain-related factors contributing to muscle inhibition in patients with chronic low back pain: an experimental investigation based on superimposed electrical stimulation. Clin J Pain 2005;21(3):232-40.

Vercoulen JH, Bazelmans E, Swanink CM, Galama JM, Jongen PJ, Hommes $\mathrm{O}$, et al. Physical activity in chronic fatigue syndrome: assessment and its role in fatigue. J Psychiat Res 1997;31(6):661-73

Vlaeyen JWS, Kole-Snijders AM, Rotteveel AR, Ruesink R, Heuts PH. The role of fear of movement/(re)injury in pain disability. J Occup Rehabil 1995;5(4):235-52.

Vlaeyen JWS, Kole-Snijders AMJ, Boeren RGB, van Eek H. Fear of movement/(re)injury in chronic low back pain and its relation to behavioural performance. Pain 1995;62:363-72.

Vlaeyen JW, de Jong J, Geilen M, Heuts PH, van Breukelen G. The treatment of fear of movement (re)injury in chronic low back pain: further evidence on the effectiveness of exposure in vivo. Clin J Pain 2002;18(4):251-61.

World Health Organization. International classification of impairments, disabilities and handicaps, Geneva; 1980.

Wittink H, Hoskins Michel T, Wagner A, Sukiennik A, Rogers W. Deconditioning in patients with chronic low back pain. Fact or Fiction? Spine 2000;25(17):2221-8.

Zitman FG, Griez EJL, Hooijer C. Standaardisering depressievragenlijsten. Tijdschr Psychiatr 1989;31:114-35. 